\title{
No changes in adolescent's sedentary behaviour across Europe between 2002 and 2017
}

J. López-Fernández ${ }^{1,2}$ (D) A. López-Valenciano ${ }^{2,3 *}$, X. Mayo $^{2,3}$, G. Liguori ${ }^{4}$, M. A. Lamb ${ }^{5,6}$, R. J. Copeland ${ }^{6,7}$ and A. Jiménez $2,3,6$

\begin{abstract}
Background: Public health organizations have been alerted to the high levels of sedentary behaviour (SB) among adolescents as well as to the health and social consequences of excess sedentary time. However, SB changes of the European Union (EU) adolescents over time have not been reported yet. This study aimed to identify SB of the EU adolescents (15-17 years) in four-time points (2002, 2005, 2013 and 2017) and to analyse the prevalence of SB according to the sex.

Methods: SB of 2542 adolescents (1335 boys and 1207 girls) as a whole sample and country-by-country was analysed in 2002, 2005, 2013, and 2017 using the Sport and Physical Activity EU Special Eurobarometers' data. SB was measured using the sitting time question from the short version of the International Physical Activity Questionnaire (IPAQ), such that 4h30min of daily sitting time was the delineating point to determine excess SB behaviour ( $\geq 4 \mathrm{~h} 30 \mathrm{~min}$ of sitting time) or not ( $\leq 4 \mathrm{~h} 30 \mathrm{~min}$ of sitting time). A $\times 2$ test was used to compare the prevalence of SB between survey years. Furthermore, SB prevalence between sexes was analysed using a Z-Score test for two population proportions.

Results: The prevalence of SB among EU adolescents across each of the four survey years ranged from 74.2 and $76.8 \%$, rates that are considered high. High levels of SB were also displayed by both sexes (girls: 76.8 to $81.2 \%$; boys: 71.7 to 76.7\%). No significant differences in the prevalence of SB among years ( $p>0.05)$ were found for the whole sample, and for either girls or boys. Also, no significant differences in the prevalence of SB between girls and boys were found.

Conclusion: The SB prevalence in European adolescents is extremely high (76.8\% in 2017) with no differences between girls and boys. No significant improvements have been seen between 2002 and 2017. Eurobarometer should increase the adolescents' sample to make possible benchmarking comparisons among the EU countries and extend the survey to the younger children population.
\end{abstract}

Keywords: Sedentarism, Sitting, Youth, National policies

\footnotetext{
* Correspondence: alejandro.valenciano@urjc.es

${ }^{2} \mathrm{GO}$ fit LAB, Ingesport, Madrid, Spain

${ }^{3}$ Observatory of Healthy \& Active Living of Spain Active Foundation, Centre

for Sport Studies, King Juan Carlos University, Madrid, Spain

Full list of author information is available at the end of the article
}

(c) The Author(s). 2021 Open Access This article is licensed under a Creative Commons Attribution 4.0 International License, which permits use, sharing, adaptation, distribution and reproduction in any medium or format, as long as you give appropriate credit to the original author(s) and the source, provide a link to the Creative Commons licence, and indicate if changes were made. The images or other third party material in this article are included in the article's Creative Commons licence, unless indicated otherwise in a credit line to the material. If material is not included in the article's Creative Commons licence and your intended use is not permitted by statutory regulation or exceeds the permitted use, you will need to obtain permission directly from the copyright holder. To view a copy of this licence, visit http://creativecommons.org/licenses/by/4.0/ The Creative Commons Public Domain Dedication waiver (http://creativecommons.org/publicdomain/zero/1.0/) applies to the data made available in this article, unless otherwise stated in a credit line to the data. 


\section{Background}

Sedentary behaviour (SB) represents those behaviours performed in sitting or lying position with a low level of energy expenditure ( $\leq 1.5$ metabolic equivalent of tasks [METs]) [1]. In adolescents, these behaviours represent between 60 and $70 \%$ of daily time spent awake [2-4]. SB has become one of the main risk factors for weight and adiposity weight [5-7], psychological health problems (e.g., anxiety, depression, aggression, attention problems) $[8,9]$, and is also seen as increasing the vulnerability to suicide in adolescents [10]. Furthermore, evidence concludes that SB adopted during adolescence will be maintained into adulthood [11] and it is therefore a strong predictor of cardiovascular diseases later in life [12, 13].

Although there is no sufficient evidence for SB's determinants in young people [14], adolescents spend prolonged periods of their awake time sitting in controlled, required, environments such as schools $[15,16]$, which thereby hinders the possibility of limiting SB time. Alongside this, the electronic revolution has transformed people's movement patterns, significantly increasing the amount of daily time in front of the screen (e.g., televisions, computers, smartphones, etc.) $[17,18]$, and by sex, girls usually report a slightly higher prevalence of SB than boys [3]. Furthermore, there seem to be sex differences in how SB is accumulated, with boys reporting more screen time (televisions or computer games) and girls spending more time in communication-based SB (surfing the internet, texting, talking on the phone) [17, 18]. For those reasons, concerns among parents, health care professionals, governments, educators, and researchers about SB's effects on young people's health have increased.

Despite this, to our knowledge, by the time this paper was written, there was not a European guideline or policy about SB in adolescents. It was not until 2020 when the World Health Organization (WHO) included the first SB recommendations within their guidelines for adolescents ("limit the amount of time spent being sedentary, particularly the amount of recreational screen time" [19]). There was a previous SB guideline published by the WHO but, for children under 5 years old [20]. It was not until 2011 when the first national SB guideline for children and adolescents was published, in Canada [21], providing an important and timely recommendation for advancing of SB public health agenda. Regarding the EU, despite the recommendations to reduce $\mathrm{SB}$ in school-age children from the EU Physical Activity Guidelines in 2008 [22], only a few countries (e.g., Germany, France, Spain, or United Kingdom) have included some actions since then to reduce SB in their national guidelines [23-25]. However, none of these guidelines have included sex-related recommendations [26]. Furthermore, most of the reports about PA from the EU countries, which include an evaluation of the SB indicators about the compliance of the no more than 2$\mathrm{h}$ screen time recommendations, show poor compliance with the existing guidelines [27]. Therefore, organizations and governments should place a greater emphasis on reducing SB during adolescence [28] through the establishment of guidelines and policies with specific goals and key performance indicators, and this should be done with consideration to sex-based differences in SB [11, 29].

Based on this, it is relevant to monitor the SB of European adolescents across different time-points. This is especially important since the WHO's Global Action Plans emphasises the need to implement effective and coordinated actions aiming to reduce SB for both adults and children [30, 31]. However, the lack of studies monitoring the prevalence of SB prevents the establishment of a baseline, therefore determining long-term objectives and success [30, 31]. The Special Eurobarometer, in which the International Questionnaire of Physical Activity (IPAQ) is administered, might be a good opportunity to identify this baseline point in the EU and for analysing the effect of future policy development on SB in the mid and long term. In fact, the IPAQ questionnaire asks about daily sitting time, which has proved to be useful for analysing the prevalence of SB in European adults and for evaluating over different time periods [32, 33].

This study aimed to analyse the SB prevalence in EU adolescents (15-17 years) between 2002 and 2017, considering data from the four separate Sport and Physical Activity Eurobarometer's data. A secondary objective of this research was to compare the prevalence of $\mathrm{SB}$ according to the sex.

\section{Methods}

\section{Data source}

All methods were carried out in accordance with relevant guidelines and regulations. The European Commission conducts public opinion surveys simultaneously on all EU state members to identify the levels of PA, sports participation, and SB among its citizens through the Sport and Physical Activity and Health and Food Special Eurobarometers. These Eurobarometer surveys were conducted using a multi-stage sampling, random design. In order to cover the whole territory of the country, the number of sampling points was drawn with probability proportional to both population size and population density.

For the purposes of this study, data from adolescents (15-17 years old) were obtained from four successive Eurobarometer surveys, December 2002 (Special Eurobarometer 183.6; $n=543$ ), December 2005 (Special Eurobarometer 246; $n=929$ ), December 2013 (Special Eurobarometer 412; $n=592$ ), and December 2017 (Special Eurobarometer 472; $n=478$ ), with a final sample of 2542 adolescents (1207 girls and 1335 boys) from the 28 European Union member 
countries (Austria, Belgium, Bulgaria, Czech Republic, Croatia, Cyprus Republic, Denmark, Estonia, Finland, France, Germany [combined West and East Deutschland], Great Britain, Greece, Hungary, Ireland, Italy, Latvia, Lithuania, Luxembourg, Malta, Netherlands, Poland, Portugal, Romania, Slovakia, Slovenia, Spain, and Sweden). Data from Northern Cyprus and Turkey were not analysed because they do not belong to the EU member countries. Following the methodology used in previous studies using Eurobarometer data, Northern Ireland was not considered because the sample size from this region was too high compared to the sample from the UK [32].

\section{Measures}

The IPAQ is a valid and reliable questionnaire to obtain data on SB [34]. The IPAQ short form records PA at three intensity levels along with the total sitting time on an average day (i.e., How much time do you spend sitting on a usual day? This may include time spent at a desk, visiting friends, studying, or watching television?). In the 2002 and 2005 surveys, participants were asked to estimate their usual weekday sitting time using an openended response scale. On the contrary, for the 2013 and 2017 surveys, participants were given a choice of 11 categorical response options ranging from ' $\leq 60$ mins' to '>8h30mins'.

For this study, surpassing the cut-off point of $4 \mathrm{~h}$ and 30 min of sitting time was considered as SB. This value was based on the cut-off point for increased risk of cardiovascular diseases [35, 36]. Individuals answering "don't know" on the sitting question were removed from the analysis.

\section{Statistical analysis}

Descriptive statistics presented as a proportion (\%) with the $95 \%$ confidence interval $(95 \% \mathrm{CI})$ were calculated for the SB dichotomic variable. The $\chi^{2}$ test was implemented for studying the association between sedentary lifestyle (SB and non-SB) with the studied years (2002, 2005, 2013, and 2017). Due to the number of EU countries increasing from 15 to 28 in 2004, two analysis were performed. The first analysis compared outcomes from 2002 to 2017 considering data from all countries participating in each Special Eurobarometer. The second analysis also compared the outcomes from 2002 to 2017 but only considering the data from the first 15 countries [32]. The differences by sex in SB for each studied year were analysed using a Z-Score for two population proportions. A priori alpha level was set at 0.05 . Z-score analyses were performed with Microsoft Excel version 1709 (Microsoft Corporation; Redmond, Washington, United States of America). The remaining analyses were performed using the Statistical Package for Social Sciences (version 22.0, SPSS Inc., Chicago, IL, USA).

\section{Results}

Table 1 displays the descriptive outcomes for non-SB and $\mathrm{SB}$ among the studied years for each of the analysed countries. The rates of SB across the four survey years were high as they ranged from 74.2 and $76.8 \%$. High levels of SB across these four years were also displayed by both sexes (girls: 76.8 to $81.2 \%$; boys: 71.7 to $76.7 \%$ ).

No significant differences among years were found in the prevalence of SB for the whole sample $(n=2542$; $\mathrm{x} 2=4375 ; \mathrm{DF}=3 ; p=0.224)$, for girls $(n=1207 ; \mathrm{x} 2=$ $2671 ; \mathrm{DF}=3 ; p=0.445)$ or for boys $(n=1335 ; \mathrm{X} 2=2415$; $\mathrm{DF}=3 ; p=0.491)$ (Fig. 1). The outcomes considering the first $15 \mathrm{EU}$ countries did not reveal differences throughout the studied time points for either the whole sample $\left[n=1596 ; \mathrm{X}^{2}=2665 ; \mathrm{DF}=3 ; p=0.446\right]$, for girls $[n=762$; $\left.\mathrm{X}^{2}=2553 ; \mathrm{DF}=3 ; p=0.466\right]$, or for boys $[n=834 ; \mathrm{\chi} 2=$ $1280 ; \mathrm{DF}=3 ; p=0.734]$ ). No differences in the prevalence of SB between girls and boys were found in the studied time point (2002 [Z-Score $=1.33 ; p=0.18] ; 2005$ [Z-Score $=1.64 ; p=0.10] ; 2013$ [Z-Score $=1.76 ; p=0.08]$; 2017 [Z-Score $=0.62 ; p=0.53]$.

\section{Discussion}

This study examined the data from the existing Eurobarometer reports in order to analyse how the SB prevalence in European adolescents has changed over 15 years (2002-2017) and if differences between girls and boys existed. The main findings were that (a) although EU adolescents showed high levels of SB, the prevalence of SB between 2005 and 2017 remains similar (74.2 to $76.8 \% ; p>0.05)$ with no significant differences over time for girls or boys; (b) girls and boys show similar prevalence of SB in all studied years.

Previous research has assessed the prevalence of adult SB across European populations based on 2002, 2005, 2013 and 2017 Eurobarometer data [32, 33, 37] but, to the best of our knowledge, this is the first study focused on adolescents. The Global Matrix project can be used to identify the percentage of European adolescents exceeding the 2-h of recreational screen time per day [27]. However, the total daily SB performed by European adolescents was still missing, and this research provides an initial approach to mend this gap. A high proportion of European adolescents, $76.8 \%$ in 2017, reported sitting times in excess of $4 \mathrm{~h} 30 \mathrm{~min}$, which is the threshold for SB. These rates of SB are higher than what has been reported for adults from the Eurobarometer data sets [32]. Unlike adults, however, this study did not reveal significant differences by sex in the prevalence of SB [32].

Although secondary-school is compulsory until the age of 16, most adolescents still attend secondary-school centres or other educational centres until the age of 18 , so their time there may account for the high percentage of SB in adolescents. Thus, although some exceptions 


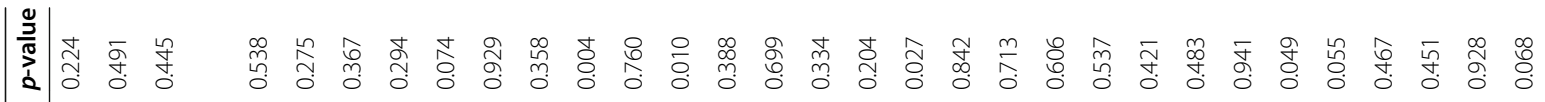
文

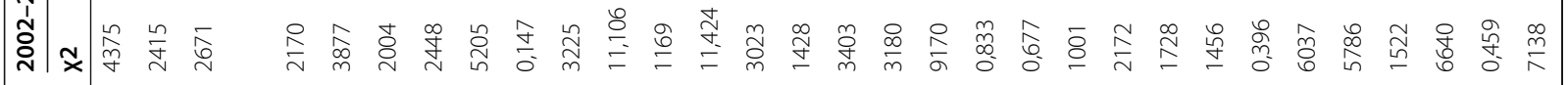

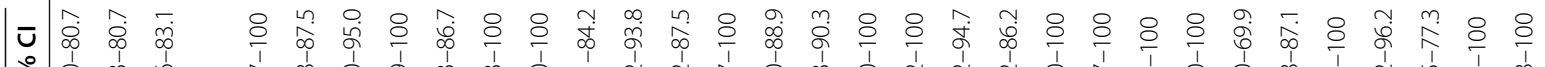

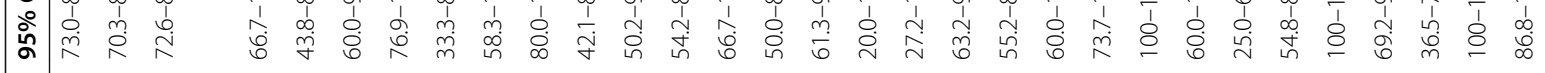

$\frac{\hat{\sigma}}{\bar{c}}$ ஸे

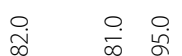

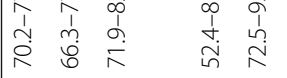

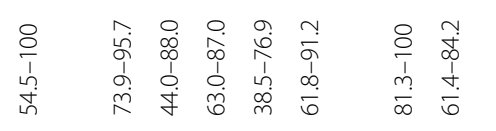

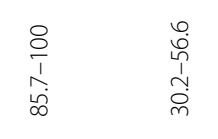

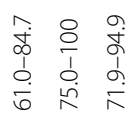

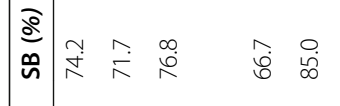

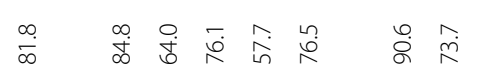

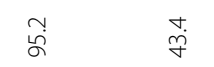

ฏิ

$\bar{\sim}$

n

in $\simeq$ m 


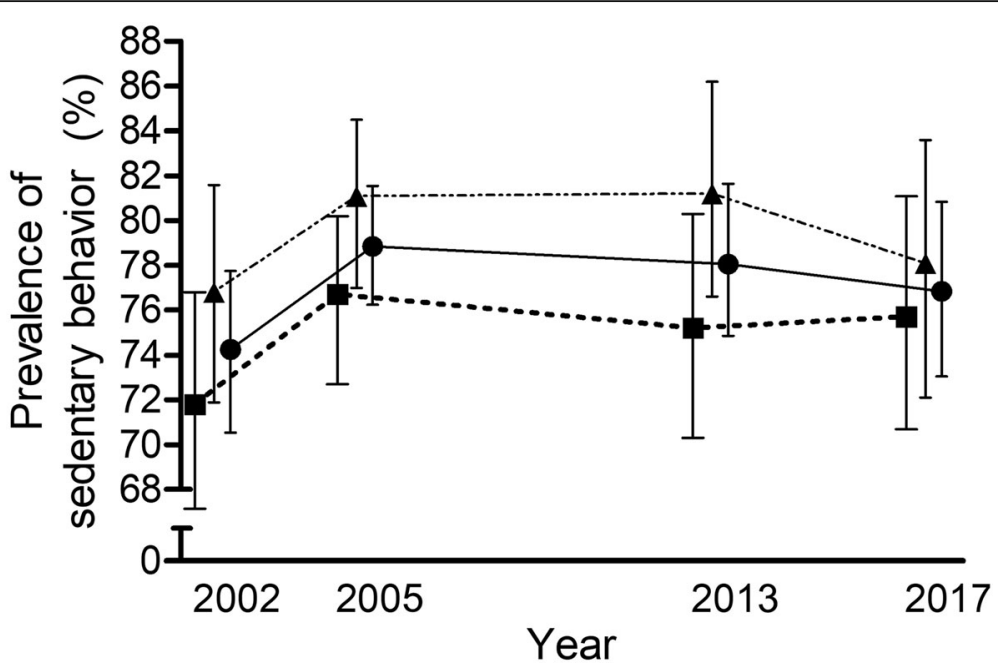

Fig. 1 Prevalence of sedentary behaviour among European Union adolescents for the four studied time-points Prevalence (\%) of sedentary behaviour ( $>4 \mathrm{~h} 30 \mathrm{~min} /$ day) among European Union adolescents (in circles, the whole sample; in triangles, the girls' sample; and in squares, the boys' sample) for four different time-points $(2002,2005,2013$, and 2017). Data are means $\pm \mathrm{Cl}$

might exist (physical education classes, laboratory work, fieldwork, some technology or art classes, etc.), adolescents at school tend to accumulate more than $5 \mathrm{~h}$ of $\mathrm{SB}$ just during a typical school day [38]. This may also at least partly explain the lack of differences across the years, the lack of difference between sexes, and the higher prevalence of SB of adolescents compared to adults. After-school activities may also play a significant role in the total sitting time accrued, as adolescents spend an average of $59 \%$ of their after-school time in sedentary activities (from 27.7 to $88.9 \%$ ) and screenrelated activities usually represent the main sedentary activity [39]). Thus, to develop and analyse the impact of future policies and interventions addressing $\mathrm{SB}$ in adolescents, a distinction between sedentary behaviour at school and in free time should also be made. Furthermore, they type of sedentary activity should be also considered (e.g., screen-related activity; educationally related; socially related activity; etc.). These two considerations cannot be made through the IPAQ questionnaire, so a different instrument might be needed.

Regarding sex differences, most existing studies with adolescents suggest that girls accrue higher average sitting time than boys [38, 40-42]. The findings from our study are not in line with this, as no sex differences were seen in any of the study years. The lack of differences may be due to SB being self-reported, as opposed to more objective data such as from an accelerometer $[33,37]$. Another possible explanation of the lack of sex differences might be the low sample size in the Special Eurobarometers as previous studies reported that girls and boys engage differently in sedentary activities, with boys reporting more TV or computer games, and girls reporting more time in communication or social media activities $[17,18]$. Thus, further studies are needed to verify or reject the findings reported in our study.

To the best of the authors' knowledge, only seven of the 28 EU countries (Austria, Belgium, Finland, France, Germany, Spain and The UK) included some kind of reference for sedentariness for children and youth in their national guidelines before publication of the latest Eurobarometer report (2017) [23-25, 43-47]. This is in contrast to the EU Working Group "Sport and Health" recommendations in 2008 to reduce SB in school-age children [22]. Moreover, the existing reports about PA from the EU countries show a high percentage of adolescents exceeding 2-h of screen-based entertainment per day [27], but do not monitor the daily sitting time of this same population. Since 2017, more European countries have developed or updated national guidelines related to SB in adolescents (Greece, Dutch, Latvia or the UK [48-51]). Nonetheless, other than recommendations like that exist in France ("children between 6-17 years old should not accumulate sitting bouts for $>2$-h long") [44], most other existing guidelines only mention SB under a qualitative perspective $[43,45-49]$, with quantitative recommendations mainly focused on screen-related activities.

\section{Limitation and strengths}

This study has some limitations to be acknowledged: (a) Less than 600 adolescents were reported in three of the four Eurobarometer reports, so findings should be analysed carefully; in this regard, the sample size from each country is that small (varies between 13 to 58) that they should not be used to set the prevalence of SB for a given EU country in a particular year. Thus, benchmarking 
comparisons among countries is not possible either [32, 33], while no data were available for adolescents under 15 years; (b) SB was measured by a single self-reported question that is included within the IPAQ questionnaire, which is likely to underestimate the sitting time of adolescents [52]. However, as suggested with older adults, the use of the IPAQ Short form in this study should be valid as we compare groups within and between years instead of on individual basis [53]; (c) it is important to note that the sitting question of the IPAQ short version from 2002 to 2005 was an open solution of the total sitting time in a weekday, whilst, from the 2013 onwards the possible answers were closed to several categorical response options [54]. Finally, the existing reports do not distinguish between SB pattern or where they occur (at the educational centre or out the educational centre). Thus, future Eurobarometer surveys might consider making an extra effort to 1) get enough representation to allow both benchmark comparisons among European countries and strengthen the comparison analysis between girls and boys; 2) target other children population (i.e. pubertal, prepuberal or young children); 3) monitor the engagement on the most common sedentary activities for each under 18 years old group and be able to collect SB patterns; 4) monitor the sitting behaviour either at or out the educative centre.

Despite these limitations, it is important to consider that it is the first work that assess the prevalence of SB in European Union adolescents among four different time-points and provides an initial approach to the studied research question. It is expected that this initial approach provides a significant insight for European researchers, guideline developers, and policy makers in developing new strategies to address SB among European adolescents. Finally, this work has identified some limitations in Eurobaromenter reports that might be relevant to be addressed in future reports (e.g., low sample size or only adolescents are being monitored).

\section{Conclusions}

European adolescents show worrying levels of SB regardless of their sex and no improvements have been achieved between 2002 to 2017. Likewise, girls and boys reported similar values of SB. European policy should develop guidelines to reduce this prevalence and set a common SB reduction target. Finally, European commission should increase the adolescents' sample in the Eurobarometer reports to make possible benchmarking comparisons among the EU countries and extend the survey to younger children population.

\section{Abbreviations}

Cl: Confidence interval; EU: European Union; IPAQ: International Physical Activity Questionnaire; METs: Metabolic equivalent of tasks; SB: Sedentary behaviour; UK: United Kingdom; WHO: World Health Organization

\section{Acknowledgements}

Not applicable.

\section{Authors' contributions}

J.L-F., A.L-V., X.M. and A.J. conceived and designed the study, J.L-F. and A.L-V. analysed the data. J.L-F., A.L-V., X.M. and A.J. interpreted the data. J.L-F., A.L-V., X.M., G.L., M.A.L., R.J.C. and A.J. drafted the manuscript. J.L-F., A.L-V., X.M., G.L., M.A.L., R.J.C. and A.J. critically revised the manuscript and approved the final version of the manuscript.

\section{Funding}

This paper arises from the mobility program "On the Move" granted by the Society of Spanish Researchers in the United Kingdom to X.M. The funder had no role in study design, data collection and analysis, interpretation of data, decision to publish, or preparation of the manuscript.

\section{Availability of data and materials}

The raw data is owned by the European Commission and available online (Special Eurobarometer 183-6, December 2002: https://dbk.gesis.org/dbksearch/ sdesc2.asp? no=3886\&search=58.2\&search2=\&field=all\&field2=all\&DB=e\&tab= $0 \&$ notabs $=\& n f=1 \& a f=\& \| 1=10$. Special Eurobarometer 246, December 2005: https://dbk.gesis.org/dbksearch/sdesc2.asp?no=4415\&search=64.3\&search2= \&field $=$ all\&field $2=\& D B=e \& t a b=0 \&$ notabs $=\& n f=1 \& a f=\& \|=10$. Special

Eurobarometer 412, March 2014: https:/dbk.gesis.org/dbksearch/sdesc2. asp?no=5877\&search=Physical\%20fitness\%20and\%20exercise\&search2=\&field= all \&field $2=\& D B=e \& t a b=0 \&$ notabs $=\& n f=1 \& a f=\& \|=10$. Special Eurobarometer 472 , March 2018: https://dbk.gesis.org/dbksearch/sdesc2.asp?no=6939\&search= Physical\%20fitness\%20and\%20exercise\&search2=\&field=all\&field2=\&DB=e\&tab= 0\&notabs $=\&$ nf $=1 \& a f=\&\|1\|=10$ ).

\section{Declarations}

Ethics approval and consent to participate

Not applicable because the raw data used in this study has been published by the European Commission and it is public access.

\section{Consent for publication}

Not applicable because the raw data used in this study has been published by the European Commission and it is public access.

\section{Competing interests}

Authors report no completing interest to disclose.

\section{Author details}

${ }^{1}$ Centre for Exercise, Sport and Life Sciences (CSELS), Coventry University, Coventry, West Midlands, UK. ${ }^{2} \mathrm{GO}$ fit LAB, Ingesport, Madrid, Spain.

${ }^{3}$ Observatory of Healthy \& Active Living of Spain Active Foundation, Centre for Sport Studies, King Juan Carlos University, Madrid, Spain. ${ }^{4}$ The College of Health Sciences, University of Rhode Island, Kingston, RI, USA. ${ }^{5}$ Centre for Behavioural Science and Applied Psychology, Sheffield Hallam University, Sheffield, UK. ${ }^{6}$ Advanced Well-Being Research Centre, Sheffield Hallam University, Sheffield, UK. ${ }^{7}$ The National Centre for Sport and Exercise Medicine, Sheffield, UK.

Received: 19 November 2020 Accepted: 13 April 2021

Published online: 23 April 2021

\section{References}

1. Tremblay MS, Aubert S, Barnes JD, Saunders TJ, Carson V, Latimer-Cheung $A E$, et al. Sedentary behavior research network (SBRN) - terminology consensus project process and outcome. Int J Behav Nutr Phys Act. 2017; 14(1):75. https://doi.org/10.1186/s12966-017-0525-8.

2. Chaput JP, Carson VG. C. E., Tremblay MS: importance of all movement behaviors in a 24 hour period for overall health. Int J Environ Res Public Health. 2014;11(12):12575-81. https://doi.org/10.3390/ijerph111212575.

3. Cooper AR, Goodman A, Page AS, Sherar LB, Esliger DW, van Sluijs EM, et al. Objectively measured physical activity and sedentary time in youth: the International children's accelerometry database (ICAD). Int J Behav Nutr Phys Act. 2015;12(113).

4. Owen N, Salmon J, Koohsari MJ, Turrell G, Giles-Corti B. Sedentary behaviour and health: mapping environmental and social contexts to underpin 
chronic disease prevention. Br J Sports Med. 2014;48(3):174-7. https://doi. org/10.1136/bjsports-2013-093107.

5. Kolle E, Ekelund U. Is sitting time a strong predictor of weight gain? Curr Obes Rep. 2013;2(1):77-85. https://doi.org/10.1007/s13679-012-0039-2.

6. Must A, Tybor DJ. Physical activity and sedentary behavior: a review of longitudinal studies of weight and adiposity in youth. Int J Obes. 2005;29(2): S84-96. https://doi.org/10.1038/sj.ijo.0803064.

7. Tremblay MS, LeBlanc AG, Kho ME, Saunders TJ, Larouche R, Colley RC, et al. Systematic review of sedentary behaviour and health indicators in schoolaged children and youth. Int J Behav Nutr Phys Act. 2011;8(98).

8. Hoare E, Milton K, Foster C, Allender S. The associations between sedentary behaviour and mental health among adolescents: a systematic review. Int J Behav Nutr Phys Act. 2016;13(1):108. https://doi.org/10.1186/s12966-0160432-4.

9. Stiglic N, Viner RM. 1. BMJ Open. 2019;9:e23191.

10. Uddin R, Burton NW, Maple M, Khan SR, Tremblay MS, Khan A. Low physical activity and high sedentary behaviour are associated with adolescents' suicidal vulnerability: evidence from 52 low- and middle-income countries. Acta Paediatr. 2019.

11. Biddle SJ, Pearson N, Ross GM, Braithwaite RE. Tracking of sedentary behaviours of young people: a systematic review. Prev Med. 2010;51(5):34551. https://doi.org/10.1016/j.ypmed.2010.07.018.

12. Cliff DP, Hesketh KD, Vella SA, Hinkley T, Tsiros MD, Ridgers ND, et al. Objectively measured sedentary behaviour and health and development in children and adolescents: systematic review and meta-analysis. Obes Rev. 2016;17(4):330-44. https://doi.org/10.1111/obr.12371.

13. Thorp AA, Owen N, Neuhaus M, Dunstan DW. Sedentary behaviors and subsequent health outcomes in adults a systematic review of longitudinal studies, 1996-2011. Am J Prev Med. 2011;41(2):207-15. https://doi.org/10.101 6/j.amepre.2011.05.004

14. Deliens T, Deforche B, De Bourdeaudhuij I, Clarys P. Determinants of physical activity and sedentary behaviour in university students: a qualitative study using focus group discussions. BMC Public Health. 2015;15(201).

15. Abbott RA, Straker LM, Erik Mathiassen S. Patterning of children's sedentary time at and away from school. Obes. 2013;21(1):E131-3. https://doi.org/10.1 002/oby.20127.

16. Carson V, Cliff DP, Janssen X, Okely AD. Longitudinal levels and bouts of sedentary time among adolescent girls. BMC Pediatr. 2013;13(173).

17. Barr-Anderson DJ, Sisson SB. Media use and sedentary behavior in adolescents: what do we know, what has been done, and where do we go? Adolesc Med State Art Rev. 2012;23(3):511-28.

18. de Moraes Ferrari GL, Pires C, Solé D, Matsudo V, Katzmarzyk PT, Fisberg M. Factors associated with objectively measured total sedentary time and screen time in children aged 9-11 years. J Pediatr. 2019;95(1):94-105. https://doi.org/10.1016/j.jped.2017.12.003.

19. World Health Organization. WHO guidelines on physical activity and sedentary behaviour. Geneva: World Health Organization; 2020.

20. World Health Organization. Guidelines on physical activity, sedentary behaviour and sleep for children under 5 years of age. Washington, D.C World Health Organization; 2019.

21. Tremblay MS, LeBlanc AG, Janssen I, Kho ME, Hicks A, Murumets K, et al. Canadian sedentary behaviour guidelines for children and youth. Appl Physiol Nutr Metab. 2011:36(1):59-64. https://doi.org/10.1139/H11-012.

22. EU Working Group Sport and Health. EU Physical Activity Guidelines Recommended Policy Actions in Support of Health-Enhancing Physical Activity. Brussels: European Commission; 2008.

23. Chief Medical Office. FACTSHEET 3. Physical activity guidelines for children and young people (5-18 years). London: Department of Health and Social Care; 2011.

24. Ministerio de Sanidad SSel. Actividad Física para la Salud y Reducción del Sedentarismo. Recomendaciones para la población. Estrategia de Promoción de la Salud y Prevención en el SNS. Madrid: Gobierno de España; 2015.

25. Rütten A, Pfeifer K. Nationale Empfehlungen für Bewegung und Bewegungsförderung. In. Bavaria: Friedrich-Alexander-Universität ErlangenNürnberg; 2016.

26. Liwander A, Pederson A, Boyle E. Why the Canadian sedentary behaviour guidelines should reflect sex and gender. Can J Public Health. 2013;104(7): e479-81. https://doi.org/10.17269/cjph.104.4108.

27. Aubert S, Barnes JD, Aguilar-Farias N, Cardon G, Chang CK, Nyström CD, et al. Report card grades on the physical activity of children and youth comparing 30 very high human development index countries. J Phys Act Health. 2018;15(s2):S298-314. https://doi.org/10.1123/jpah.2018-0431.

28. Fernandez-Jimenez R, Al-Kazaz M, Jaslow R, Carvajal I, Fuster V. Children present a window of opportunity for promoting health: JACC review topic of the week. J Am Coll Cardiol. 2018;72(25):3310-9. https://doi.org/10.1016/j. jacc.2018.10.031.

29. Maniccia DM, Davison KK, Marshall SJ, Manganello JA, Dennison BA. A metaanalysis of interventions that target Children's screen time for reduction. Pediatr. 2011;128(1):e193-210. https://doi.org/10.1542/peds.2010-2353.

30. World Health Organization. Global action plan for the prevention and control of noncommunicable diseases 2013-2020. Geneva: World Health Organization; 2013.

31. World Health Organization. Global action plan on physical activity 20182030: more active people for a healthier world. Geneva: World Health Organization; 2018.

32. López-Valenciano A, Mayo X, Liguori G, Copeland RJ, Lamb M, Jimenez A. Sedentary behaviour increases in European Union adults between 2002 and 2017. BMC Public Health. 2020;20:1-10.

33. Milton K, Gale J, Stamatakis E, Bauman A. Trends in prolonged sitting time among European adults: 27 country analysis. Prev Med. 2015;77:11-6. https://doi.org/10.1016/j.ypmed.2015.04.016.

34. Craig CL, Marshall AL, Sjöström M, Bauman AE, Booth ML, Ainsworth BE, et al. International physical activity questionnaire: 12-country reliability and validity. Med Sci Sports Exerc. 2003;35(8):1381-95. https://doi.org/10.1249/01. MSS.0000078924.61453.FB.

35. Ekelund U, Steene-Johannessen J, Brown WJ, Fagerland MW, Owen N, Powell $\mathrm{KE}$, et al. Lancet physical activity series 2 executive Committe., lancet sedentary behaviour working group.: does physical activity attenuate, or even eliminate, the detrimental association of sitting time with mortality? A harmonised metaanalysis of data from more than 1 million men and women. Lancet. 2016; 388(10051):1302-10. https://doi.org/10.1016/50140-6736(16)30370-1.

36. Stamatakis E, Gale J, Bauman A, Ekelund U, Hamer M, Ding D. Sitting time, physical activity, and risk of mortality in adults. J Am Coll Cardiol. 2019; 73(16):2062-72. https://doi.org/10.1016/j.jacc.2019.02.031.

37. Jelsma JG, Gale J, Loyen A, van Nassau F, Bauman A, van der Ploeg HP. Time trends between 2002 and 2017 in correlates of self-reported sitting time in European adults. PLoS One. 2019;14(11):e0225228. https://doi.org/1 0.1371/journal.pone.0225228

38. da Costa BGG, da Silva KS, Malheiros LEA, Minatto G, de Lima LRA, Petroski EL. Are adolescents really being sedentary or inactive when at school? An analysis of sedentary behaviour and physical activity bouts. Eur J Pediatr. 2018;177(11):1705-10. https://doi.org/10.1007/s00431-018-3233-8.

39. Arundell L, Fletcher E, Salmon J, Veitch J, Hinkley T. A systematic review of the prevalence of sedentary behavior during the after-school period among children aged 5-18 years. Int J Behav Nutr Phys Act. 2016;13(93).

40. Hansen BH, Kolle E, Steene-Johannessen J, Dalene KE, Ekelund U, Anderssen SA. Monitoring population levels of physical activity and sedentary time in Norway across the lifespan. Scand J Med Sci Sports. 2019;29(1):105-12. https://doi.org/10.1111/sms.13314.

41. Hoffmann B, Kobel S, Wartha O, Kettner S, Dreyhaupt J, Steinacker JM. High sedentary time in children is not only due to screen media use: a crosssectional study. BMC Pediatr. 2019:19(154).

42. Silva RMA, Andrade ACDS, Caiaffa WT, Medeiros DSD, Bezerra VM. Nationa Adolescent School-based Health Survey-PeNSE 2015: sedentary behavior and its correlates. PLoS One. 2020;15(1):e0228373. https://doi.org/10.1371/ journal.pone.0228373.

43. Gelius P, Tcymbal A, Abu-Omar K, Mendes R, Morais ST, Whiting S, et al. Status and contents of physical activity recommendations in European Union countries: a systematic comparative analysis. BMJ Open. 2020;10:1-14.

44. I'Agence nationale de sécurité sanitaire de l'alimentation dleedt: Actualisation des repères du PNNS - Révisions des repères relatifs l'activité physique et la sédentarité [Revisions of benchmarks relating to physical activity and sedentary lifestyle]. In. Edited by l'Agence nationale de sécurité sanitaire de l'alimentation dleedt; 2016

45. Ministerie van Welzijn VeG: Vlaamse consensustekst in verband met evenwichtige voeding en beweging, ten behoeve van zorgverstrekkers [Flemish consensus text on a balanced diet and exercise, for the benefit of healthcare providers]. In. Brussel: Ministerie van Welzijn, Volksgezondheid en Gezin; 2012

46. Opetusministeriö.: Fyysisen aktiivisuuden suositus kouluikäisille 7-18vuotiaille [Physical activity recommendation for school-aged 7-18 year olds]. In. Edited by Opetusministeriö; 2008. 
47. Kahlmeier S, Wijnhoven TM, Alpiger P, Schweizer C, Breda J, Martin BW. National physical activity recommendations: systematic overview and analysis of the situation in European countries. BMC Public Health. 2015; 15(133):1-14.

48. Gibson-Moore H. UK chief medical officers' physical activity guidelines 2019: What's new and how can we get people more active? Nutr Bull. 2019;44(4): 320-8. https://doi.org/10.1111/nbu.12409.

49. Weggemans RM, Backx FJ, Borghouts L, Chinapaw M, Hopman MT, Koster A, et al. The 2017 Dutch physical activity guidelines. Int J Behav Nutr Phys Act. 2018;15(58).

50. Latvijas Republikas Veselïbas ministrija.: Fizisko aktivităšu ieteikumi Latvijas iedzivotājiem [Recommendations for physical activity for the people of Latvia]. In. Edited by ministrija LRV; 2019.

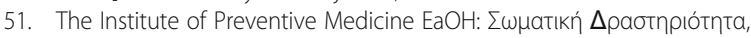

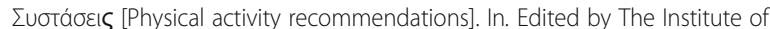
Preventive Medicine $\mathrm{EaOH} ; 2017$.

52. Rääsk T, Mäestu J, Lätt E, Jürimäe J, Jürimäe T, Vainik U, et al. Comparison of IPAQ-SF and two other physical activity questionnaires with accelerometer in adolescent boys. PLoS One. 2017;12(1):e0169527. https://doi.org/10.1371/ journal.pone.0169527.

53. Cleland C, Ferguson S, Ellis G, Hunter RF. Validity of the International Physical Activity Questionnaire (IPAQ) for assessing moderate-to-vigorous physical activity and sedentary behaviour of older adults in the United Kingdom. BMC Med Res Methodol. 2018;18(176).

54. Buck C, Loyen A, Foraita R, Van Cauwenberg J, De Craemer M, Mac Donncha $C$, et al. Factors influencing sedentary behaviour: a system based analysis using Bayesian networks within DEDIPAC. PLoS One. 2019;14(1): e0211546. https://doi.org/10.1371/journal.pone.0211546.

\section{Publisher's Note}

Springer Nature remains neutral with regard to jurisdictional claims in published maps and institutional affiliations.

Ready to submit your research? Choose BMC and benefit from:

- fast, convenient online submission

- thorough peer review by experienced researchers in your field

- rapid publication on acceptance

- support for research data, including large and complex data types

- gold Open Access which fosters wider collaboration and increased citations

- maximum visibility for your research: over $100 \mathrm{M}$ website views per year

At $\mathrm{BMC}$, research is always in progress.

Learn more biomedcentral.com/submissions 